\title{
Mycobacterium immunogenum sp. nov., a novel species related to Mycobacterium abscessus and associated with clinical disease, pseudo- outbreaks and contaminated metalworking fluids: an international cooperative study on mycobacterial taxonomy
}

\footnotetext{
1,2 Center for Pulmonary and Infectious Disease Control ${ }^{1}$ and Department of Microbiology ${ }^{2}$, The University of Texas Health Center, 11937 US Hwy 271, Tyler, TX 75708, USA

3 Institut für Medizinische Mikrobiologie, Medizinische Hochschule Hanover, 30623 Hanover, Germany

4 Institut Pasteur, Centre National de Reference des Mycobacteries, Paris, France

5 Texas Department of Health, Austin, TX, USA

${ }^{6}$ Departmento de Medicina Preventiva, Facultad de Medicina, Universidad Autonoma de Madrid, Spain

7 BioSan Laboratories, Warren, MI, USA
}

\author{
Rebecca W. Wilson, ${ }^{1,2}$ Vincent A. Steingrube, ${ }^{2}$ Erik C. Böttger, ${ }^{3}$ \\ Burkhard Springer, ${ }^{3}$ Barbara A. Brown-Elliott, ${ }^{2}$ Véronique Vincent, ${ }^{4}$ \\ Kenneth C. Jost, Jr, ${ }^{5}$ Yansheng Zhang, ${ }^{2}$ Maria J. Garcia, ${ }^{6}$ Sher H. Chiu, ${ }^{5}$ \\ Grace O. Onyi, ${ }^{2}$ Harold Rossmoore, ${ }^{7}$ Donald R. Nash ${ }^{1}$ \\ and Richard J. Wallace, $\mathrm{Jr}^{1,2}$
}

\begin{abstract}
Author for correspondence: Rebecca W. Wilson. Tel: +1 903877 7680. Fax: +1 9038777652. e-mail: becky.wilson@uthct.edu
\end{abstract}

\begin{abstract}
PCR-restriction enzyme pattern analysis of a 439 bp hsp65 gene segment identified 113 unique isolates among non-pigmented rapidly growing mycobacteria (RGM) from clinical and environmental sources that failed to match currently recognized species patterns. This group represented $40 \%$ of isolates recovered from bronchoscope contamination pseudo-outbreaks, $0 \%$ of disease-associated nosocomial outbreaks and $4 \%$ of routine clinical isolates of the Mycobacterium abscessus/Mycobacterium chelonae group submitted to the Mycobacteria/Nocardia laboratory for identification. It is grouped within the Mycobacterium fortuitum complex, with growth in less than $7 \mathrm{~d}$, absence of pigmentation, positive 3-d arylsulfatase reaction and growth on MacConkey agar without crystal violet. It exhibited overlapping biochemical, antimicrobial susceptibility and HPLC characteristics of $M$. abscessus and $M$. chelonae. By $16 S$ rRNA gene sequencing, these isolates comprised a homogeneous group with a unique hypervariable region $A$ sequence and differed by 8 and 10 bp, respectively, from $M$. abscessus and $M$. chelonae. Surprisingly, this taxon contained two copies of the ribosomal operon, compared with single copies in the two related species. By DNA-DNA hybridization, this new group exhibited $<30 \%$ homology with recognized RGM species. The name Mycobacterium immunogenum sp. nov. is proposed for this new taxon.
\end{abstract}

Keywords: Mycobacterium immunogenum, rapidly growing mycobacterium, mycobacterium taxonomy, metalworking fluids

\section{INTRODUCTION}

Mycobacterium abscessus, Mycobacterium chelonae and Mycobacterium mucogenicum have been the most

\footnotetext{
Abbreviations: $\mathrm{BAL}$, bronchoalveolar lavage; HP, hypersensitivity pneumonitis; MWF, metalworking fluid; PRA, PCR-restriction enzyme pattern analysis; RGM, rapidly growing mycobacteria.

The EMBL accession number for the 16S rDNA sequence of strain ATCC 700506 is AJ011771.
}

commonly recovered mycobacteria involved in waterborne nosocomial outbreaks and pseudo-outbreaks (Band et al., 1982; Fraser et al., 1992; Maloney et al., 1994; Petersen et al., 1994; Wallace et al., 1993a, b) and metalworking fluid (MWF)-associated hypersensitivity pneumonitis (HP) (Kreiss \& Cox-Ganser, 1997; Muilenberg et al., 1993). These rapidly growing mycobacterial (RGM) species are more resistant to free chlorine than are coliform bacteria (Carson et al., 1988a; Collins et al., 1984). They are found, along 
with other environmental species of mycobacteria (Picardeau et al., 1997), in 83-90\% of samples from domestic water-purification systems (Carson et al., 1988a; Schulze-Röbbecke et al., 1992). They are prevalent in biofilms (Schulze-Röbbecke et al., 1992), are relatively resistant to disinfecting agents such as $2 \%$ alkaline glutaraldehyde and up to $8 \%$ formaldehyde (Carson et al., 1978) and are able to grow in distilled-water supplies (Carson et al., 1978). These characteristics enhance the capacity of these organisms to survive and proliferate in hospital water systems, which are the source of most nosocomial non-tuberculous mycobacterial outbreaks (Band et al., 1982; Bernstein et al., 1995; Hoffman et al., 1981; Kuritsky et al., 1993; Szabo \& Sarkozi, 1980; Villaneuva et al., 1997).

HP has been characterized as a granulomatous lung disease similar to sarcoidosis and beryllium disease (Kreiss \& Cox-Ganser, 1997). Since the first reported case in 1991, a total of 98 cases of HP have been associated with exposure of industrial workers to aerosolized water-based synthetic, semi-synthetic or soluble oil MWF (Kreiss \& Cox-Ganser, 1997). While the HP generally resolved upon removal of patients from the MWF environment, a small number of cases were reported to have chronic interstitial lung disease and some had biopsy evidence of fibrosis. The complex microbial flora of used MWFs, acid-fast bacteria in particular, have been implicated as the aetiological agent of HP (Kreiss \& Cox-Ganser, 1997).

The taxonomy and epidemiology of RGM and their involvement in nosocomial outbreaks and pseudooutbreaks have been a major focus of the Mycobacteria/Nocardia Laboratory at the University of Texas Health Center at Tyler (UTHCT). Biochemical, antimicrobial susceptibility and PCRrestriction enzyme analysis (PRA) testing of mycobacterial isolates recovered from several outbreaks, some involving MWFs, have resulted in the identification of a group of isolates that produced a hybrid pattern of phenotypic and genotypic characteristics that were common to both $M$. abscessus and $M$. chelonae. The potential of these environmental and nosocomial pseudo-outbreak isolates to cause human disease (Kreiss \& Cox-Ganser, 1997) prompted further examination, in order to determine their relationship to the established mycobacterial pathogens $M$. abscessus and M. chelonae.

\section{METHODS}

Organisms. The first of these unusual isolates were recognized during a study of the use of PRA for taxonomic identification of clinical mycobacteria (Wilson et al., 1998). These isolates exhibited PRA band patterns from a $439 \mathrm{bp}$ segment of the hsp65 gene (Telenti et al., 1993) that appeared to be a hybrid between those of $M$. chelonae and $M$. abscessus. The PRA pattern obtained with BstEII was characteristic for M. chelonae, while the HaeIII pattern was characteristic for M. abscessus. Environmental isolates with the same hybrid PRA pattern were subsequently identified as part of an environmental study of contaminated MWF, a portion of which has been published (Moore et al., 2000) (see Table 1). Most isolates had high minimum inhibitory concentrations (MICs) for tobramycin and cefoxitin, so isolates within our culture collection with the same susceptibility pattern were screened by PRA. Based on DNA fingerprinting results of 10 previous nosocomial outbreaks of disease and 10 pseudo-breaks involving M. abscessus and/or M. chelonae (Wallace et al., 1993a; Zhang et al., 1997), one isolate representative of each outbreak pattern was selected and screened by PRA.

In 10 selected previous mycobacterial nosocomial outbreaks associated with disease (Szabo \& Sarkozi, 1980; Hoffman et al., 1981; Lowry et al., 1988; Kuritsky et al., 1993; Wallace et al., 1993a; Bernstein et al., 1995; Villanueva et al., 1997), based on PRA species identification, M. abscessus was the predominant species, accounting for 9 of $10(90 \%)$ outbreaks previously identified by biochemical testing as being due to $M$. abscessus or $M$. chelonae. $M$. chelonae was responsible for 1 of $10(10 \%)$ of the outbreaks. The new taxon was not identified in any of these nosocomial outbreaks. Conversely, among the 10 pseudo-outbreaks studied, based on PRA species identification, strains of the new taxon were found in 5 of $10(50 \%)$ water-related pseudo-outbreaks (Moore et al., 2000; Fraser et al., 1992; Wallace et al., 1993a), compared with 2 of $10(20 \%)$ that involved M. abscessus (Kuritsky et al., 1993; Wallace et al., 1998). One additional PRA pattern was identified in 3 of 10 $(30 \%)$ water-related pseudo-outbreaks (referred to as new taxon II in Fig. 3) (Maloney et al., 1994; Petersen et al., 1994) and was not studied further. M. chelonae was not identified in any of the pseudo-outbreaks.

Clinical isolates belonging to the M. chelonae/M. abscessus group submitted for identification were also screened for the new taxon pattern by PRA. Among 165 clinical isolates identified as members of the $M$. abscessus $/ M$. chelonae group, $67 \%$ were $M$. abscessus, $30 \%$ were $M$. chelonae and $4 \%$ belonged to the new taxon.

A total of 112 isolates were identified that exhibited the $M$. chelonae/M. abscessus hybrid PRA pattern. This included 98 environmental isolates from MWF, two isolates from five separate nosocomial pseudo-outbreaks involving contaminated bronchoscopes in Missouri (MC 779) (Maloney et al., 1994) and Maryland (MC 926) (Wallace et al., 1993a), one environmental isolate from the Midwest and 11 clinical isolates isolated from skin, cornea, urine, joint fluid, bronchoalveolar lavage (BAL) fluid, Groshong exit site, pacemaker pocket, Broviac site and blood (catheter site) submitted to the UTHCT Mycobacteria/Nocardia laboratory for susceptibility testing (Table 1).

Control isolates included randomly chosen clinical isolates submitted to the UTHCT laboratory for identification by PRA (Wilson et al., 1997) and susceptibility testing, as well as reference isolates from the ATCC (Manassas, VA, USA). These comprised $11 \mathrm{M}$. abscessus isolates, including the type strain ATCC $19977^{\mathrm{T}}$, and 13 M. chelonae isolates, including ATCC 35749, ATCC 35751 and the type strain, ATCC $35752^{\mathrm{T}}$.

Phenotypic characteristics. Isolates were tested for their ability to utilize citrate, D-glucitol (D-sorbitol), i-myoinositol and D-mannitol as sole carbon sources according to the methods of Tsukamura (1981, 1984). Tests for 3-d arylsulfatase activity, iron uptake, nitrate reductase activity and growth on MacConkey agar without crystal violet were performed according to standard methods (Kent \& Kubica, 
Table 1. Clinical characteristics of isolates of the new taxon of RGM

Isolates MC 779 , MC 926 and MC 1991 have been reported previously, by Fraser et al. (1992), Wallace et al. (1993a) and Moore et al. (2000), respectively.

\begin{tabular}{|c|c|c|c|c|}
\hline Isolate & Source & Disease & Location & Comments \\
\hline \multicolumn{5}{|l|}{ Environmental isolates } \\
\hline $\operatorname{MC} 779^{\mathrm{T}}\left(=\mathrm{ATCC} 700505^{\mathrm{T}}\right)$ & BAL fluid & None & Missouri & $\begin{array}{l}\text { Pseudo-outbreak. Isolates } \\
\text { highly resistant to } \\
\text { cefoxitin }\end{array}$ \\
\hline MC 926 & BAL fluid & None & Maryland & Pseudo-outbreak \\
\hline MC 1903 & Hospital environment & Unknown & Midwest USA & \\
\hline MC 1991 (= ATCC 700506) & MWF & & Wisconsin & \\
\hline MC 1993 & MWF & & - & \\
\hline MC 1995 & MWF & & - & \\
\hline MC 1996 & MWF & & - & \\
\hline MC 2233 & MWF & & - & \\
\hline MC 2234 & Environment & & - & \\
\hline MC 2236 & MWF & & - & \\
\hline MC 2240 & MWF & & - & \\
\hline MC 2241 & Environment & & - & Formaldehyde resistant \\
\hline MC 2268 & Environment & & - & \\
\hline \multicolumn{5}{|l|}{ Clinical isolates } \\
\hline MC 835 & Skin & $\begin{array}{l}\text { Disseminated cutaneous } \\
\text { infection }\end{array}$ & Texas & SCID \\
\hline MC 1878 & Cornea & Suspected keratitis & Texas & No clinical data available \\
\hline MC 1911 & Urine & Unknown & Florida & No clinical data available \\
\hline MC 1988 & $\begin{array}{l}\text { Intravenous catheter } \\
\text { site (Groshong) }\end{array}$ & Catheter-related infection & Texas & $\begin{array}{l}\text { Host immune status } \\
\text { unknown }\end{array}$ \\
\hline MC 2110 & $\begin{array}{l}\text { Hand-aspirated } \\
\text { joint fluid }\end{array}$ & Septic joint & Texas & Normal host \\
\hline MC 2230 & BAL fluid & Chronic pneumonia & Texas & SCID \\
\hline MC 2181 & $\begin{array}{l}\text { Intravenous catheter } \\
\text { site, blood }\end{array}$ & Catheter-related sepsis & Iowa & Bone-marrow transplant \\
\hline MC 2462 & $\begin{array}{l}\text { Pacemaker pocket, } \\
\text { blood }\end{array}$ & Pacemaker-related sepsis & Michigan & Normal host \\
\hline MC 2540 & Broviac site & Catheter-related infection & Massachusetts & Acute leukaemia \\
\hline MC 2570 & Skin & $\begin{array}{l}\text { Disseminated cutaneous } \\
\text { infection }\end{array}$ & Louisiana & Liver transplant \\
\hline MC 2605 & Blood & Unknown & N. Carolina & No clinical data available \\
\hline
\end{tabular}

SCID, Severe combined immunodeficiency syndrome.

1985). Growth on Löwenstein-Jensen medium containing $5 \% \mathrm{NaCl}$ (Kent \& Kubica, 1985) was tested at both 30 and $35^{\circ} \mathrm{C}$.

MIC values were determined for amikacin, cefoxitin, cefmetazole, ciprofloxacin, clarithromycin, doxycycline, imipenem, sulfamethoxazole and tobramycin by a broth microdilution method in cation-supplemented MüllerHinton broth (Swenson et al., 1985; Wallace et al., 1993b). Disc-diffusion zone sizes for polymyxin b $(10 \mu \mathrm{g})$, amikacin $(30 \mu \mathrm{g})$ and kanamycin $(30 \mu \mathrm{g})$ were determined using Müller-Hinton agar swabbed with oleic acid, albumin and dextrose and incubation for $3 \mathrm{~d}$ at $30^{\circ} \mathrm{C}$.

Genomic restriction endonuclease digestion and pulsed field gel electrophoresis (PFGE) analysis. All isolates of the new taxon were examined for genetic strain relatedness of their large restriction fragment (LRF) patterns by PFGE
(Tenover et al., 1995). Genomic DNA was prepared and LRF patterns were obtained by restriction endonuclease digestions with $D r a \mathrm{I}$ and $X b a \mathrm{I}$, with separation by PFGE according to methods described previously (Wallace et al., 1993a). Strain relatedness was defined according to the methods of Tenover et al. (1995).

Fluorescence detection (FL)-HPLC. Ten strains of the new taxon, strains 2649, 2642 ${ }^{\mathrm{T}}\left(=\mathrm{ATCC} 700505^{\mathrm{T}}\right), 2648,2645$, 2623, 2647, 2646 (=ATCC 700506), 2652, 2644 and 2651, were analysed by FL-HPLC. Ten reference strains of $M$. abscessus, strains 2612, 2603, 0203 ${ }^{\mathrm{T}}$ (= ATCC 19977 $)$, 2605, 2600, 2611, 2608, 2607, 2606 and 2602, and 10 reference strains of $M$. chelonae, strains $0187^{\mathrm{T}}$ (= ATCC 35752 $), 0189$ (= ATCC 19236), 0188, 0183 (=ATCC 35749), 0195, 0186, 0194, 0185, 0191 and 0190, were used as comparative strains. For HPLC analysis, isolates were obtained from the ATCC or from the HPLC Users Group 
Steering Committee (Butler et al., 1996a, b). Mycobacterial isolates were analysed by FL-HPLC according to the method of Jost \& Dunbar (1992) and Jost et al. (1995) with the modifications described by Brown et al. (1999). The method of Butler \& Kilburn (1990) was used to number chromatographic peaks and to calculate peak-height ratios.

PCR amplification for PRA. DNA from cells was prepared for PCR amplification as described previously (Steingrube et al., 1995a; Telenti et al., 1993; Wilson et al., 1998). A 439 bp segment of the $h s p 65$ gene was amplified from mycobacterial ground-cell supernatants, together with the appropriate positive and negative controls, according to a modification of the method of Telenti et al. (1993) (Steingrube et al., 1995a; Wilson et al., 1998).

PRA. Six restriction endonucleases, BstEII, HaeIII, HhaI, MspI, HinfI and BsaHI (New England Biolabs and Promega), were used to produce PRA band patterns using methods described previously (Steingrube et al., 1995a, b, c, 1997; Wilson et al., 1997). Fragments of $\leqslant 60$ bp were disregarded and restriction fragment sizes were rounded to the nearest $5 \mathrm{bp}$, as recommended by Telenti et al. (1993).

Sequence determination of 16S rRNA gene. The 16S rRNA gene regions chosen for analysis were based on published sequence data available in the EMBL/GenBank database (Kazda et al., 1992; Kirschner et al., 1992a, b, 1993a, b; Pitulle et al., 1992; Rogall et al., 1990; Stahl \& Urbance, 1990). GenBank accession numbers for selected 16S rRNA gene sequences used for comparison were as follows: Mycobacterium fortuitum ATCC $6841^{\mathrm{T}}$, X52933; $M$. abscessus ATCC $19977^{\mathrm{T}}$, X82235; and M. chelonae ATCC $35752^{\mathrm{T}}, \mathrm{X} 82236$.

The methods used for DNA extraction, amplification of $16 \mathrm{~S}$ rRNA gene fragments and sequence determination have been described previously (Hultman et al., 1989; Kirschner et al., 1993a, b). The sequences obtained were aligned with selected 16S rRNA gene sequences as described previously (Rogall et al., 1990).

For phylogenetic analyses, only $16 \mathrm{~S}$ rRNA gene regions that were available for the rapidly growing species were included (corresponding to Escherichia coli positions 126-554, 894-1084 and 1101-1332). Pairwise distances (Hamming distances) were calculated by weighting nucleotide differences and insertions/deletions equally. A phylogenetic tree was constructed using the neighbourliness method as described previously (Rogall et al., 1990).

Sequence determination of hsp65 gene. The hsp65 gene region selected for analysis was described by Telenti et al. (1993). The methods used for DNA extraction, amplification, sequence determination and construction of the phylogenetic tree were described previously (Ringuet et al., 1999).

DNA-DNA hybridization. DNA-DNA homology experiments were performed as described previously (Domenech et al., 1997). Genomic DNA (0.5 $\mu \mathrm{g})$ was labelled in vitro using a nick-translation labelling kit (Boehringer Mannheim) and $30 \mu \mathrm{Ci}\left[\alpha-{ }^{32} \mathrm{P}\right] \mathrm{dCTP}$ (Amersham).

Portions $(1 \mu \mathrm{g})$ of each unlabelled DNA were bound to nylon membrane filters (Amersham) by alkaline denaturation and UV fixation. Hybridizations were carried out under stringent conditions for $40 \mathrm{~h}$. Filters were washed and counted with a liquid scintillation counter (Beckman). The relative binding ratios for each strain were calculated from the counts of homologous DNA bound and were expressed as percentages.
RFLP analysis of the 16S rRNA gene. RFLP analysis of the $16 \mathrm{~S}$ rRNA gene was performed using genomic DNA digested with BamHI and PstI. The digests were separated by electrophoresis on horizontal gels containing $0.75 \%$ $(\mathrm{w} / \mathrm{v})$ agarose and then transferred to nylon membrane filters (Amersham).

An $804 \mathrm{bp}$ fragment of the 16S rRNA gene of the $M$. fortuitum type strain, ATCC $6841^{\mathrm{T}}$, was obtained by PCR and used as a probe. For DNA amplification, the Rcl and Rc2 oligonucleotide sequences from the Mycobacterium bovis BCG 16S rRNA gene sequence were used in $50 \mu \mathrm{l}$ amplification mixtures as described previously (Domenech et al., 1997). The cycling profile consisted of 30 cycles of $1 \mathrm{~min}$ at $94{ }^{\circ} \mathrm{C}, 30 \mathrm{~s}$ at $58^{\circ} \mathrm{C}$ and $1 \mathrm{~min}$ at $72{ }^{\circ} \mathrm{C}$, followed by a final $5 \mathrm{~min}$ extension at $72^{\circ} \mathrm{C}$. The ribosomal probe was labelled using the prime- $\alpha$-gene system (Promega) and $20 \mu \mathrm{Ci}\left[\alpha-{ }^{32} \mathrm{P}\right] \mathrm{dCTP}$ (Amersham).

\section{RESULTS}

\section{Phenotypic characteristics}

Isolates of the new taxon had the growth and biochemical characteristics of the $M$. fortuitum complex (Silcox et al., 1981) (Table 2). This included typical morphology with acid-fast staining, the absence of pigmentation, growth on tryptic soy and Middlebrook $7 \mathrm{H} 10$ agar in less than $7 \mathrm{~d}$ incubation at 30 and $35^{\circ} \mathrm{C}$, no growth at $45^{\circ} \mathrm{C}$, growth on MacConkey agar without crystal violet and a positive 3 -d arylsulfatase reaction (Silcox et al., 1981). Most isolates grew better at 30 than at $35^{\circ} \mathrm{C}$.

These isolates appeared to be related to the $M$. abscessus/M. chelonae group, based on negative iron uptake and nitrate reductase reactions, properties common to the latter two species (Silcox et al., 1981). They exhibited some reactions typical of M. abscessus, including the inability to utilize citrate, D-glucitol (Dsorbitol), $i$-myo-inositol and D-mannitol as sole carbon sources (Silcox et al., 1981) (Table 2) and resistance to tobramycin $\left(\mathrm{MIC} \geqslant 16 \mu \mathrm{g} \mathrm{ml}^{-1}\right.$ ) (Swenson et al., 1985) (Table 3). However, they were unable to grow on Löwenstein-Jensen medium containing $5 \% \mathrm{NaCl}$ at $35^{\circ} \mathrm{C}$ (Table 2) and most isolates exhibited high levels of resistance to cefoxitin (MIC $256 \mu \mathrm{g} \mathrm{ml}^{-1}$ ), phenotypic characteristics typical of $M$. chelonae (Silcox et al., 1981; Swenson et al., 1985; Wallace et al., 1991b) (Table 3). Interestingly, isolates of both the new taxon and $M$. chelonae exhibited $25-50 \%$ growth in the presence of $5 \% \mathrm{NaCl}$ at $30{ }^{\circ} \mathrm{C}$ compared with control growth on Löwenstein-Jensen medium.

In terms of drug susceptibilities, the new taxon differed from both $M$. chelonae and $M$. abscessus. The ratio of kanamycin to amikacin disc-zone sizes for the 10 control strains of $M$. abscessus ranged from $1 \cdot 3$ to $1 \cdot 7$, with a mean of $1 \cdot 5$, while for $16 / 18$ isolates of the new taxon, the ratio was $<1.2$ with a mean of 0.92 . For the new taxon, $14 / 17$ had cefoxitin MICs of $\geqslant 256 \mu \mathrm{g} \mathrm{ml}^{-1}$ and $16 / 18$ had tobramycin MICs of $\geqslant 16 \mu \mathrm{g} \mathrm{ml}^{-1}$. All isolates of the new taxon had at least one of these features and $17 / 18(95 \%)$ had two of the three. No isolate showed any (partial or complete) zone of 
Table 2. Growth and biochemical properties of $M$. abscessus, $M$. immunogenum and $M$. chelonae

Data for clinical isolates were taken from Springer et al. (1995) and Wallace et al. (1993b). Characters are scored as: + , positive $(\geqslant 90 \%) ;-$, negative $(\leqslant 10 \%)$.

\begin{tabular}{|c|c|c|c|c|c|c|}
\hline \multirow[t]{2}{*}{ Character } & \multicolumn{2}{|c|}{ M. abscessus } & \multicolumn{2}{|c|}{ M. immunogenum } & \multicolumn{2}{|c|}{ M. chelonae } \\
\hline & $\begin{array}{l}\text { Clinical } \\
\text { isolates }\end{array}$ & $\begin{array}{l}\text { ATCC } \\
19977^{\mathrm{T}}\end{array}$ & $\begin{array}{c}\text { Ten } \\
\text { isolates }\end{array}$ & $\begin{array}{c}\text { ATCC } \\
\text { 700505 }^{\mathrm{T}}\end{array}$ & $\begin{array}{l}\text { Clinical } \\
\text { isolates }\end{array}$ & $\begin{array}{l}\text { ATCC } \\
\text { 35752 }^{\mathrm{T}}\end{array}$ \\
\hline \multicolumn{7}{|l|}{ Utilization of carbon sources: } \\
\hline Citrate & - & - & - & - & + & + \\
\hline D-Glucitol (D-sorbitol) & - & - & - & - & - & - \\
\hline i-myo-Inositol & - & - & - & - & - & - \\
\hline D-Mannitol & - & - & - & - & - & - \\
\hline 3-d Arylsulfatase activity & + & + & + & + & + & + \\
\hline Growth in presence of $5 \% \mathrm{NaCl}\left(35^{\circ} \mathrm{C}\right)$ & + & + & - & - & - & - \\
\hline Iron uptake & - & - & - & - & - & - \\
\hline Nitrate reduction & - & - & - & - & - & - \\
\hline Growth in $<7 \mathrm{~d}$ & + & + & + & + & + & + \\
\hline Pigment production & - & - & - & - & - & - \\
\hline Mycolic acids by HPLC & + & + & + & + & + & + \\
\hline
\end{tabular}

Table 3. Antimicrobial susceptibility results for $M$. abscessus, $M$. immunogenum and $M$. chelonae

Values are MICs $\left(\mu \mathrm{g} \mathrm{ml}^{-1}\right)$, expressed as modal values for groups of isolates. NT, Not tested.

\begin{tabular}{|c|c|c|c|c|c|c|c|c|c|}
\hline \multirow[t]{2}{*}{ Agent } & \multicolumn{2}{|c|}{ M. abscessus } & \multicolumn{3}{|c|}{ M. immunogenum } & \multicolumn{4}{|c|}{ M. chelonae } \\
\hline & $\begin{array}{l}\text { Ten clinical } \\
\text { isolates }\end{array}$ & $\begin{array}{l}\text { ATCC } \\
19977^{\mathrm{T}}\end{array}$ & $\begin{array}{c}\text { Ten } \\
\text { isolates }\end{array}$ & $\begin{array}{c}\text { ATCC } \\
\text { 700505 }^{\mathrm{T}}\end{array}$ & $\begin{array}{l}\text { ATCC } \\
700506\end{array}$ & $\begin{array}{l}\text { Ten clinical } \\
\text { isolates }\end{array}$ & $\begin{array}{c}\text { ATCC } \\
35749\end{array}$ & $\begin{array}{l}\text { ATCC } \\
\text { 35751* }\end{array}$ & $\begin{array}{l}\text { ATCC } \\
\text { 35752 }^{\mathrm{T}}\end{array}$ \\
\hline Amikacin & 8 & 32 & 16 & 16 & 128 & 32 & 32 & 8 & 32 \\
\hline Cefoxitin & 16 & 16 & $>256$ & $>256$ & 64 & $>256$ & $>256$ & 32 & $>256$ \\
\hline Cefmetazole & 16 & 128 & $>128$ & $>128$ & 64 & 128 & $>128$ & 32 & $>128$ \\
\hline Ciprofloxacin & 16 & $>16$ & $>16$ & 2 & $>16$ & $>16$ & $>16$ & $>16$ & 1 \\
\hline Clarithromycin & $0 \cdot 5$ & 4 & $0 \cdot 25$ & NT & $0 \cdot 125$ & $0 \cdot 25$ & $0 \cdot 25$ & $0 \cdot 25$ & 0.25 \\
\hline Doxycycline & $>128$ & $>128$ & $>128$ & 32 & $>128$ & $>128$ & 128 & $>128$ & 16 \\
\hline Imipenem & 8 & 8 & 16 & 16 & 16 & 16 & 8 & 4 & 4 \\
\hline Sulfamethoxazole & $>64$ & $>64$ & $>64$ & $>64$ & $>64$ & $>64$ & $>64$ & $>64$ & $>64$ \\
\hline Tobramycin & 16 & 16 & $>16$ & $>16$ & $>16$ & 2 & 4 & 16 & 4 \\
\hline
\end{tabular}

* By PRA, this isolate is a strain of M. abscessus.

inhibition by polymyxin b. Susceptibility results for the isolates of the new taxon are compared with isolates of $M$. chelonae and M. abscessus in Table 3.

\section{PFGE analysis}

Fourteen different LRF patterns (genotypes) of the new taxon were identified by PFGE analysis. Details of some of the MWF results have already been presented (Moore et al., 2000). The two isolates of the new taxon representative of the two nosocomial pseudo-outbreaks from contaminated bronchoscopes (MC 779 and MC 926, Table 1) were different genotypes. Nine of the 11 clinical isolates were unique genotypes, with the remaining two displaying the predominant LRF pattern seen with the environmental isolates. As observed previously (Wallace et al., 1993a), undigested genomic DNA satisfactory for PFGE analysis could be obtained from only $50 \%$ of the $M$. abscessus isolates, including those from nosocomial outbreaks, while $100 \%$ of the isolates of the new taxon in the current study produced satisfactory genomic DNA.

\section{FL-HPLC analysis}

Analysis of strains of the new taxon by FL-HPLCgenerated mycolic acid patterns identified all strains as belonging to the $M$. abscessus $/ M$. chelonae group. These strains exhibited mycolic acid elution patterns 
(a)
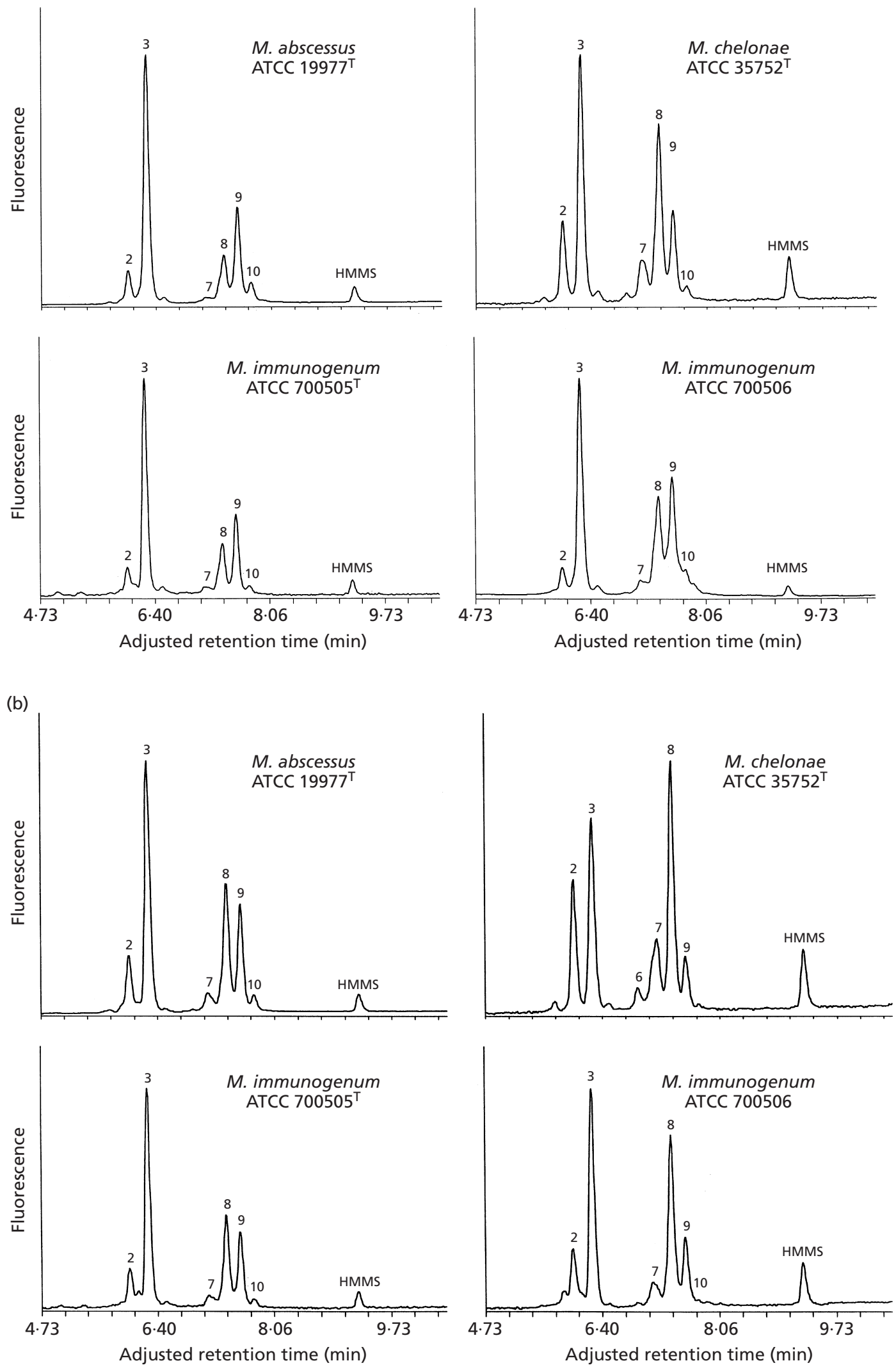

Fig. 1. Incubation-temperature-mediated variation of HPLC-generated mycolic acid 6,7-dimethoxy-4-coumarinylmethyl ester elution patterns for $M$. abscessus, $M$. chelonae and $M$. immunogenum strains grown on Löwenstein-Jensen medium at 30 (a) and 35 (b) ${ }^{\circ} \mathrm{C}$. HMMS, High molecular mass internal standard. Peaks were named using the method of Butler \& Kilburn (1990). 


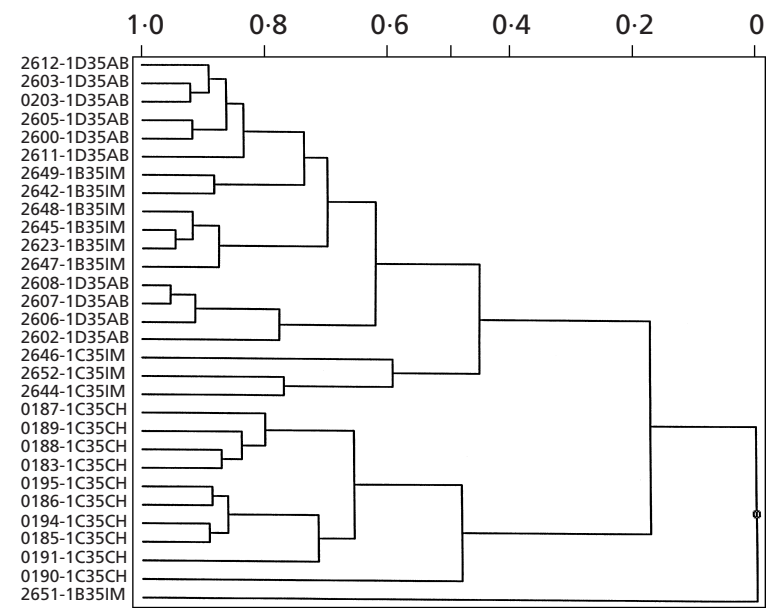

Fig. 2. Dendrogram illustrating phylogenetic relationships between $M$. abscessus, $M$. chelonae and $M$. immunogenum strains grown on Löwenstein-Jensen medium at $35^{\circ} \mathrm{C}$, based on mycolic acid composition analysis by HPLC. Suffixes $A B, C H$ and IM respectively indicate strains of $M$. abscessus, $M$. chelonae and $M$. immunogenum. The scale indicates the similarity index.

that were characterized by two peak clusters, each cluster containing two to four peaks (Fig. 1a, b). Visually, most patterns from strains of the new taxon were indistinguishable from $M$. abscessus strains, but distinct from $M$. chelonae strains. M. abscessus and $M$. chelonae strains incubated at $35^{\circ} \mathrm{C}$ produced peak $8 /$ peak 9 height ratios that ranged from 0.34 to 0.54 and 1.06 to 2.66 , respectively. The corresponding range for strains of the new taxon was $0 \cdot 25-1 \cdot 00$. Butler \& Kilburn (1990) observed peak 8/peak 9 height ratios of $\leqslant 0.86$ for M. abscessus and $\geqslant 1.00$ for M. chelonae.

Mean-centred hierarchal cluster analysis of aligned whole data obtained at $35^{\circ} \mathrm{C}$ between the two internal standard markers revealed a single distinct cluster that contained all of the strains of M. chelonae (Fig. 2). At a similarity index of $0 \cdot 70$, the $M$. abscessus strains grouped into two clusters, one of six strains and a second of four strains. At a similarity index of $0 \cdot 70$, the strains of the new taxon were more polymorphic than either M. abscessus or M. chelonae. The strains of the new taxon grouped into two clusters, with one strain unclustered. The pattern of the unclustered strains
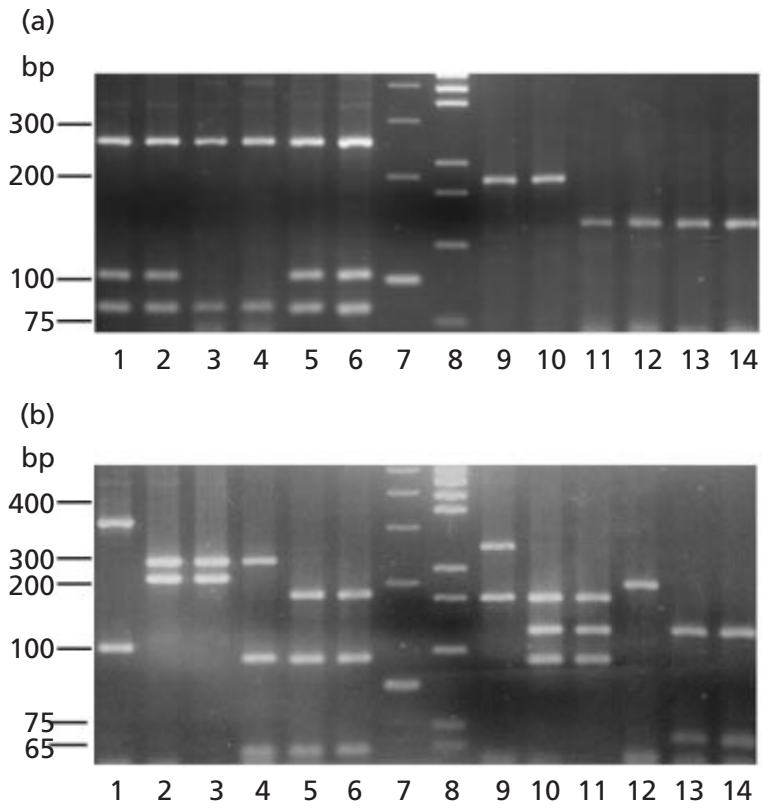

Fig. 4. Comparison of PRA patterns for $M$. chelonae, $M$. abscessus and the proposed new species, $M$. immunogenum. (a) Lanes 1-6 and 9-14: BsaHI- (lanes 1-6) and Haelll- (lanes 9-14) derived patterns for $M$. chelonae ATCC 35749 (lanes 1 and 9), M. chelonae ATCC $35752(2,10)$, M. immunogenum ATCC 700506 (3, 11), M. immunogenum MC 1995 (4, 12), M. abscessus $\operatorname{ATCC} 19977^{\top}(5,13)$ and M. abscessus MC $1148(6,14)$. Lanes 7 and 8 contain size standards (100 bp and pGEM base pair ladders). (b) BstEll- (lanes 1-3), Hhal- (4-6), Mspl- (9-11) and Haelll- (12-14) derived patterns for $M$. chelonae ATCC $35752^{\top}$ (lanes 1, 4, 9 and 12), strain ATCC 35751 (2, 5, 10 and 13) and M. abscessus ATCC $19977^{\top}(3,6,11$ and 14). Lanes 7 and 8 contain size standards (100 bp and pGEM base pair ladders).

resembled that produced by $M$. chelonae at $30^{\circ} \mathrm{C}$ and was distinct from all other patterns produced at $35^{\circ} \mathrm{C}$.

The incubation temperature exerted a pronounced effect on the HPLC patterns of $M$. abscessus, $M$. chelonae and the new taxon. Compared with patterns of strains incubated at $35^{\circ} \mathrm{C}$, patterns of the strains incubated at $30^{\circ} \mathrm{C}$ exhibited a diminished front peak cluster height relative to rear peak cluster height. Within each peak cluster, a shift in peak height towards the earlier-eluting peaks was observed. Strains of $M$. abscessus and the new taxon incubated at $30^{\circ} \mathrm{C}$ yielded patterns similar to those of $M$. chelonae strains incubated at $35^{\circ} \mathrm{C}$ (Fig. 1).

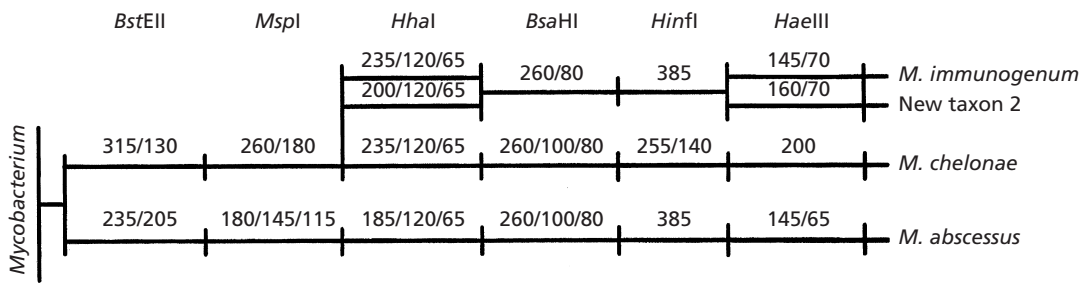

International Journal of Systematic and Evolutionary Microbiology 51
Fig. 3. Practical schematic illustrating the similarities and differences between $M$. immunogenum, new taxon 2, $M$. abscessus and $M$. chelonae by PRA of a $439 \mathrm{bp}$ segment of the hsp65 gene. PRA band sizes are expressed as the number of nucleotide bp rounded to the nearest $5 \mathrm{bp}$, as recommended by Telenti et al. (1993). 
Table 4. Signature nucleotides within hypervariable region A of the $16 \mathrm{~S}$ rRNA gene for the pathogenic RGM

The first nucleotide corresponds to E. coli position 175. M. tuberculosis is used as the reference species. Dots indicate nucleotides identical to the $M$. tuberculosis sequence. Dashes indicate the absence of insertions. Proposed or accepted type strains are indicated.

\begin{tabular}{|c|c|}
\hline Taxon/species & Signature sequence \\
\hline M. tuberculosis-M. bovis & CGGATAGG-ACCACGGGATGCATGTC-TTGTGGTG \\
\hline \multicolumn{2}{|l|}{ M. fortuitum group } \\
\hline M. fortuitum ATCC $6841^{\mathrm{T}}$ & .А..T.-....С.С.T...GT-G..... \\
\hline Mycobacterium peregrinum ATCC $14467^{\mathrm{T}}$ & .A...T.-..G..CAC.T.C..GT-G..... \\
\hline M. fortuitum third biovariant complex (sorbitol-positive) & $\ldots \ldots \ldots-\ldots \ldots$. C.T...GT-G.... \\
\hline ATCC $49403^{\mathrm{T}} ;$ M. senegalense & \\
\hline $\begin{array}{l}\text { M. fortuitum third biovariant complex } \\
\text { (sorbitol-negative) ATCC } 49404^{\mathrm{T}}\end{array}$ & .А.........СТС.T...GG-G..... \\
\hline \multicolumn{2}{|l|}{ M. chelonae/M. abscessus group } \\
\hline M. abscessus ATCC $19977^{\mathrm{T}}$ & $\ldots \ldots \ldots-\ldots \ldots \mathrm{ACAC} . \mathrm{T} \ldots \mathrm{GT}-\mathrm{GA} \ldots \ldots$ \\
\hline M. chelonae ATCC $35752^{\mathrm{T}}$ & $\ldots \ldots \ldots-\ldots . . . \mathrm{ACAC} . \mathrm{T} \ldots \mathrm{GT}-\mathrm{GA} \ldots \ldots$ \\
\hline M. immunogenum АТCC 700506 & $\ldots \ldots \ldots-\ldots$. .ATGC.T...GT-G..... \\
\hline M. mucogenicum AТCC $49650^{\mathrm{T}}$ & $\ldots$ А........С.С.T...GT-G..... \\
\hline \multicolumn{2}{|l|}{ M. smegmatis group } \\
\hline M. smegmatis sensu stricto ATCC 14468 & ..A...CACC.TG.T.TC....G.C.G..A.G. \\
\hline M. goodii ATCC $700504^{\mathrm{T}}$ & ..A...TACC.TG.T.TC.....G.C.G....G. \\
\hline M. wolinskyi ATCC $700010^{\mathrm{T}}$ & $\ldots \ldots \ldots-\ldots \ldots \mathrm{TC} \ldots \ldots \mathrm{GA}-\ldots \ldots \ldots$ \\
\hline M. mageritense ATCC $700351^{\mathrm{T}}$ & 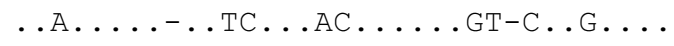 \\
\hline
\end{tabular}

\section{PRA}

Amplicons were obtained from all the isolates tested. Patterns identical to those seen with $M$. chelonae were exhibited by $98 \%(110 / 112)$ of the isolates of the new taxon after BstEII PRA and $100 \%$ of isolates after $M s p I$ and $H h a I$ PRA. Two isolates contained no BstEII restriction site (Fig. 3). Isolates of the new taxon exhibited Hinf I and HaeIII patterns that were identical to those seen with $M$. abscessus (Figs 3 and 4a, lanes 11-14) and differentiated them clearly from $M$. chelonae isolates (Figs 3 and $4 \mathrm{a}$, lanes 9 and 10). The $B s a \mathrm{HI}$ pattern of the new taxon lacked a $100 \mathrm{bp}$ band (Figs 3 and 4a, lanes 3 and 4) that was present in the common $B s a \mathrm{HI}$ pattern seen with $M$. chelonae and $M$. abscessus isolates (Figs 3 and 4a, lanes 1, 2, 5 and 6).

The three RGM isolates representing the three pseudooutbreaks from contaminated bronchoscopes, which have been recognized but not characterized at this time, exhibited a unique PRA pattern, not seen previously, consisting of a $200 \mathrm{bp}$ upper band with HhaI and a 160 bp upper band with HaeIII, compared with 235 and 145 bp bands seen with the new taxon (Fig. 3).

\section{Misidentification of ATCC 35751}

In this laboratory, M. chelonae reference isolate ATCC 35751 was found to be negative for utilization of citrate, D-glucitol (D-sorbitol), i-myo-inositol and Dmannitol as sole carbon sources and found to grow in the presence of $5 \% \mathrm{NaCl}$ (Silcox et al., 1981) (Table 2).
Results of susceptibility testing indicated that this strain was moderately susceptible to cefoxitin and resistant to tobramycin (MIC $16 \mu \mathrm{g} \mathrm{ml}^{-1}$ ), similar to values for isolates of $M$. abscessus (Swenson et al., 1985; Wallace et al., 1991b) (Table 3). In addition to phenotypic characteristics typical of $M$. abscessus, PRA of isolate ATCC 35751 with all six restriction endonucleases produced band patterns that matched those of $M$. abscessus isolates, including the $M$. abscessus type strain, ATCC $19977^{\mathrm{T}}$ (Fig. 3). This strain appears to be misidentified and is a strain of $M$. abscessus rather than $M$. chelonae. A comparison of restriction fragment patterns for the $M$. chelonae type strain, ATCC $35752^{\mathrm{T}}$, ATCC isolate 35751 and the $M$. abscessus type strain, ATCC $19977^{\mathrm{T}}$, with BstEII, HhaI, MspI and HaeIII is shown in Fig. 4(b).

\section{Sequence determination of 16S rRNA gene}

Five isolates of the new taxon were sequenced in hypervariable regions $\mathrm{A}$ and $\mathrm{B}$, with identical results. The isolates of the new taxon had a hypervariable region B that matched $M$. chelonae and M. abscessus, but a hypervariable region $\mathrm{A}$ that differed from these two species as well as all other species of RGM (Table 4). Over the sequence of the entire 16S rRNA gene, the new taxon differed by 8 and 10 bp from $M$. abscessus and $M$. chelonae, respectively, while the latter two species are known to differ from one other by 4 bp (Kirschner et al., 1993b; Springer et al., 1995). The new taxon differs by more than $35 \mathrm{bp}$ from all other species. A phylogenetic tree showed M. chelonae, 


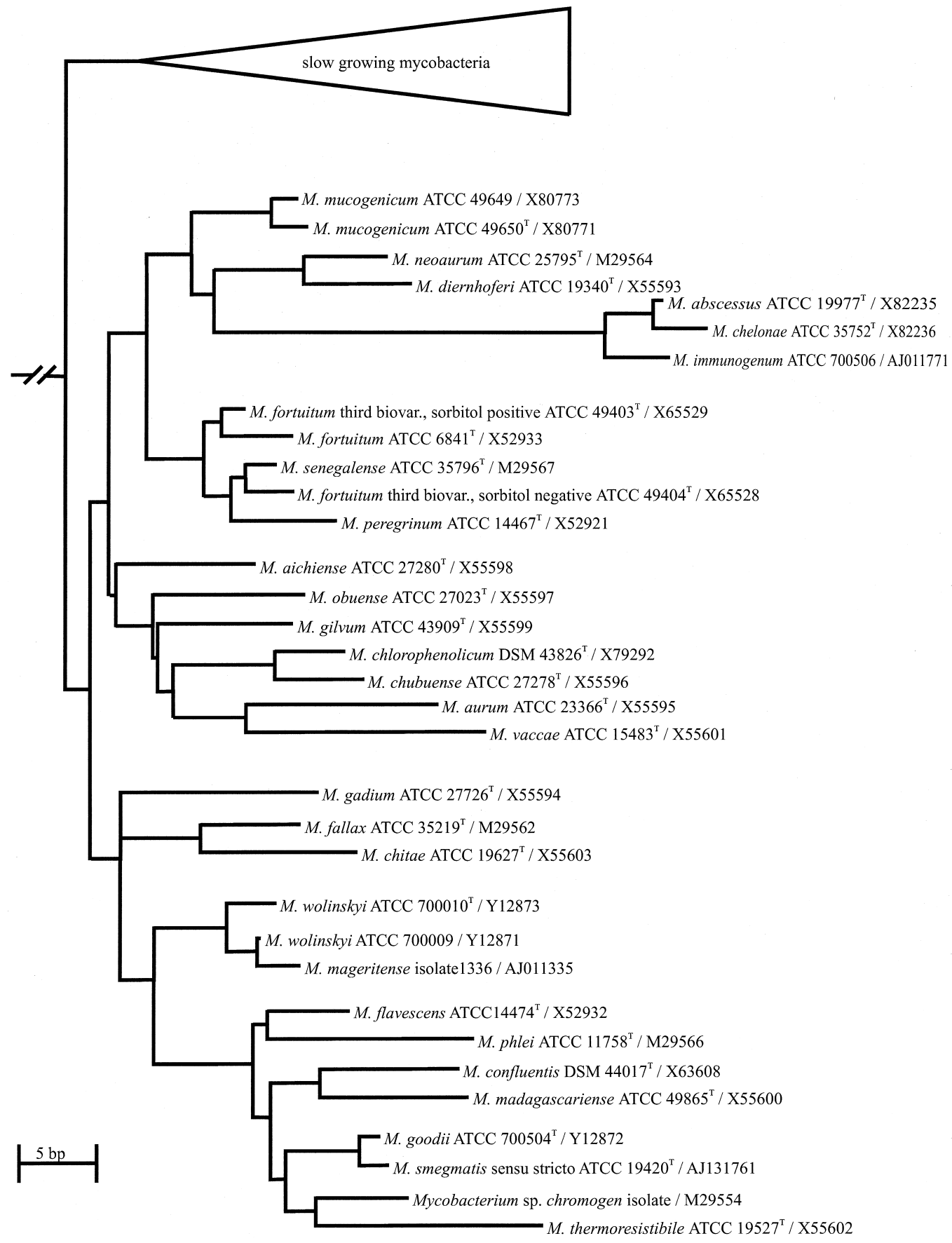

Fig. 5. Dendrogram illustrating the phylogenetic relationships on the basis of $16 \mathrm{~S}$ rRNA gene sequences among 30 species and taxa of RGM including M. immunogenum ATCC 700506, M. abscessus ATCC $19977^{\top}$ and M. chelonae ATCC $35752^{\top}$.

M. abscessus and the new taxon to occupy a separate branch of the tree, quite distant from other recognized species (Fig. 5).

\section{Sequence determination of the hsp65 gene}

The 441 bp region described by Telenti et al. (1993), from nucleotide position 396 to 836 according to the published sequence from Mycobacterium tuberculosis
(Shinnick, 1987), was investigated. The hsp65 sequences within this region differed by 21 and $33 \mathrm{bp}$, respectively, from $M$. chelonae and $M$. abscessus, while $M$. chelonae and M. abscessus differed from each other by $29 \mathrm{bp}$. As demonstrated previously, two hypervariable regions of the $h s p 65$ gene were identified, between positions 624 and 664 and positions 683 and 725. A comparison of $M$. chelonae, M. abscessus, $M$. mucogenicum and the new taxon in the first hyper- 


\begin{tabular}{|c|c|c|c|c|c|}
\hline M. tuberculosis & $A A$ & GGTCACCGAG & АСССTGCTCA & AGGGCGCCAA & GGAGGTCGA \\
\hline M. abscessus ATCC $19977^{\top}$ & - & -- & - - G - - - - G - & $-A-$ & \\
\hline M. chelonae ATCC $35752^{\top}$ & $\mathrm{GC}$ & C ....AGC & $T-T \ldots . . . G G$ & -СТC - & - \\
\hline M. immunogenum ATCC $700505^{\top}$ & -- & 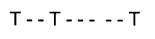 & G-C - & CT - & $\ldots$ \\
\hline M. mucogenicum ATCC $49650^{\top}$ & - - & $-\ldots-\ldots$ & - G T - . . . . & $\ldots$ & \\
\hline
\end{tabular}

Fig. 6. Alignment of hsp65 gene sequences of $M$. tuberculosis and four species of RGM in the hypervariable region (bp 624-664).
Table 5. DNA-DNA genomic pairing between $M$. immunogenum and phylogenetically related RGM

\begin{tabular}{|lc|}
\hline Test strain & $\begin{array}{c}\text { Homology with } \\
\text { ATCC } \mathbf{7 0 0 5 0 5}^{\mathrm{T}} \mathbf{( \% )}\end{array}$ \\
\hline M. immunogenum ATCC $700505^{\mathrm{T}}$ & 100 \\
M. abscessus ATCC $19977^{\mathrm{T}}$ & 15 \\
M. chelonae ATCC $35752^{\mathrm{T}}$ & 18 \\
M. fortuitum ATCC $6841^{\mathrm{T}}$ & $9 \cdot 3$ \\
M. mucogenicum ATCC $49650^{\mathrm{T}}$ & 7 \\
M. senegalense ATCC $35796^{\mathrm{T}}$ & $5 \cdot 3$ \\
\hline
\end{tabular}

variable region is shown in Fig. 6. A phylogenetic tree based on this 441 bp hsp 65 sequence obtained with 10 species of RGM and the new taxon is shown in Fig. 7 (data for the 10 recognized species were published by Ringuet et al., 1999).

\section{DNA-DNA hybridization}

DNA of the new taxon was hybridized with the following RGM reference isolates: $M$. abscessus ATCC $19977^{\mathrm{T}}$, $M$. chelonae ATCC $35752^{\mathrm{T}}, M$. fortuitum ATCC $6841^{\mathrm{T}}, M$. mucogenicum ATCC $49650^{\mathrm{T}}$ and Mycobacterium senegalense ATCC $35796^{\mathrm{T}}$. The new taxon displayed $<25 \%$ homology with the five reference strains, with the highest degree of hybridization being shown with $M$. chelonae and $M$. abscessus (Table 5).

\section{RFLP analysis of the 16S rRNA gene}

BamHI- and PstI-generated chromosomal DNA restriction fragments from the new taxon and five other species of RGM were hybridized with an $804 \mathrm{bp},{ }^{32} \mathrm{P}-$ labelled $M$. fortuitum $16 \mathrm{~S}$ rRNA probe. Each of the six species of RGM produced a unique hybridization pattern with BamHI- and PstI-generated fragments. $M$. abscessus and $M$. chelonae had only a single copy of the ribosomal genes, while the new taxon and the other three species (M. fortuitum, M. mucogenicum and $M$. senegalense) had two copies.

\section{DISCUSSION}

This proposed newest member of the $M$. fortuitum complex resembled $M$. abscessus and $M$. chelonae so closely that molecular biological methods, including PRA and 16S rRNA gene sequencing, were required for its initial recognition. This almost certainly explains the failure until now to recognize this new taxon. Biochemically and by HPLC, it is related most closely to $M$. abscessus, and it was identified as such in previous recoveries from nosocomial pseudo-outbreaks (Fraser et al., 1992; Wallace et al., 1993a). An unusual feature that differentiated isolates recovered from some pseudo-outbreaks from those of $M$. abscessus was the high level of resistance to the cephamycins cefmetazole and cefoxitin (Fraser et al., 1992).

An unexpected finding was that, despite the similarity of new taxon to $M$. chelonae and $M$. abscessus, it has two copies of the rRNA operon, while the latter two species have only one. So far, $M$. chelonae and $M$. abscessus remain the only RGM species that contain just a single copy of the operon.

Isolates of the new taxon were recovered from $40 \%$ of nosocomial pseudo-outbreaks involving contaminated automated bronchoscope washers and were present in MWF used in the metal-grinding industry (Kreiss \& Cox-Ganser, 1997). The new taxon was not identified among isolates that were recovered from 10 nosocomial outbreaks involving patient infections and were previously identified biochemically as $M$. abscessus and $M$. chelonae. The new taxon was responsible for a wide spectrum of clinical diseases (cutaneous infections, keratitis and catheter-related infections; Table 1), comparable to other species of RGM (Wallace et al., 1991a, 1993b). In addition to the 11 clinical isolates of the new taxon identified in this study, two other clinical isolates that appear to belong to the new taxon have been reported by other investigators. One isolate (M.3666/3667) was identified earlier by $16 \mathrm{~S}$ rRNA gene sequencing by one of the authors (B. Springer, unpublished), but was not available for further examination. The other isolate was designated as presumptive $M$. chelonae (Taylor et $a l ., 1997)$ and was referred to as $M$. chelonae II by Devallois et al. (1997). The latter isolate exhibited PRA patterns with BstEII and HaeIII that resembled very closely those of the new taxon in this study. These observations implicate this new mycobacterial taxon as a potential causative agent of human disease. Among clinical isolates of the $M$. abscessus $/ M$. chelonae group submitted to the UTHCT laboratory for identification, $4 \%$ were identified by PRA as members of the new taxon. FL-HPLC did not resolve the new taxon from $M$. abscessus. However, $M$. chelonae could be distinguished from M. abscessus and the new taxon by either peak-height ratio or hierarchal cluster analysis of aligned whole chromatographic data.

By $16 \mathrm{~S}$ rRNA gene sequencing, the new taxon isolates comprised a homogeneous group that exhibited a hypervariable region B sequence that was identical to 


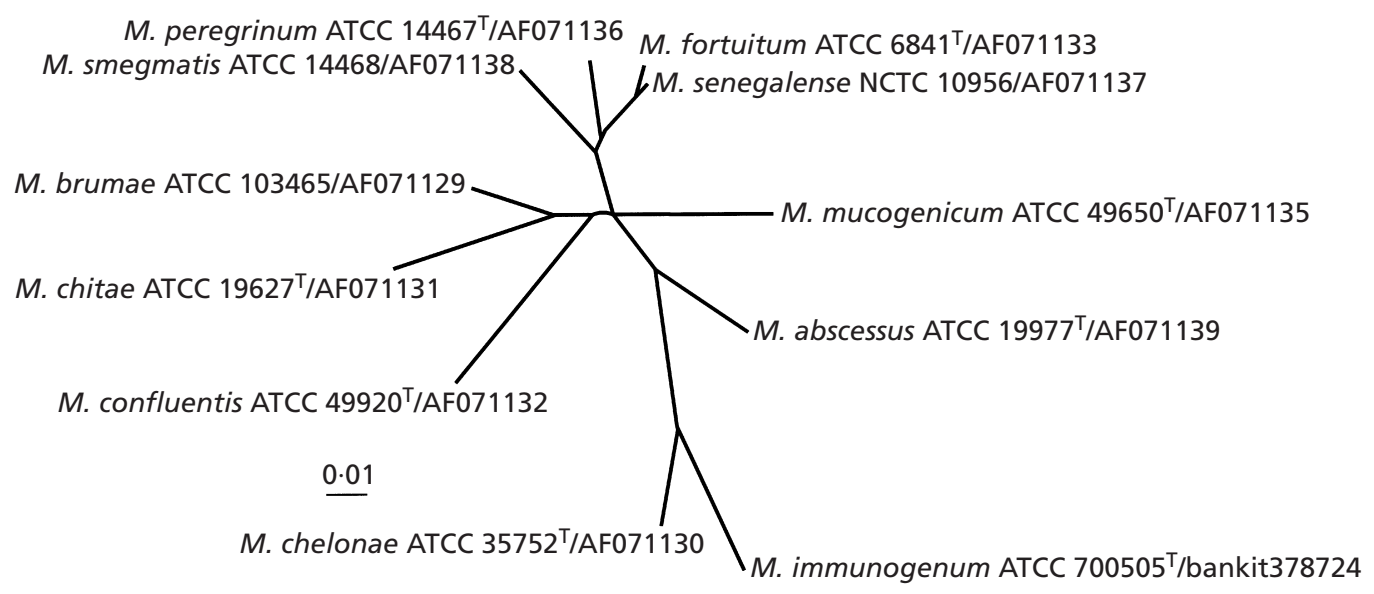

Fig. 7. Unrooted phylogenetic tree of species relatedness based on hsp65 gene sequences. Bar, $1 \%$ estimated sequence divergence.

those of M. chelonae and M. abscessus. They exhibited a unique hypervariable region A sequence, however, and the entire sequence differed by 8 and $10 \mathrm{bp}$, respectively, from M. abscessus and M. chelonae.

Among non-ribosomal genes in the RGM, hsp65 has been shown to be of special interest for taxonomic purposes (Ringuet et al., 1999; Telenti et al., 1993; Steingrube et al., 1995a, b; Swanson et al., 1996). As established previously, the $h s p 65$ gene displays more polymorphism than does the 16S rRNA gene. The $M$. chelonae and M. abscessus hsp 65 sequences differed by $29 \mathrm{bp}$ in the $441 \mathrm{bp}$ hypervariable region, whereas their 16S rRNA genes differed by only four nucleotides. Despite this, the phylogenetic tree based on hsp65 sequences was consistent with the phylogeny based on $16 \mathrm{~S}$ rRNA. Both trees showed that $M$. chelonae and $M$. abscessus are the more related species to the new taxon. However, due to the clear differentiation of $M$. chelonae and $M$. abscessus achieved by hsp65 sequencing, the $h s p 65$ tree has an enlargement effect on the phylogenetic distances among the three groups and suggested that the new taxon is more related to $M$. chelonae than to M. abscessus. The use of phylogenetic trees of hsp65 alleles from various mycobacterial species, both slowly and rapidly growing, has been reported previously (Swanson et al., 1996; Kapur et al., 1995; Ringuet et al., 1999).

In a previous report on PRA identification of RGM (Steingrube et al., 1995a, b), the only isolate of $M$. chelonae that failed to match the common PRA patterns for the species was the ATCC 35751 reference strain. More detailed examination of the original sample and a sample acquired recently from the ATCC revealed that it exhibited the biochemical, antimicrobial susceptibility and PRA pattern characteristics typical of $M$. abscessus. These data support the identification of reference strain ATCC 35751 as a strain of M. abscessus rather than M. chelonae.
Reference has been made to the difficulties involved in achieving objective, reproducible results with the biochemical tests available for the identification of aerobic actinomycetes (Devallois et al., 1997; Silcox et al., 1981; Steingrube et al., 1995c, 1997), including the distinction between $M$. abscessus and $M$. chelonae. This difficulty was evident with evaluation of growth on Löwenstein-Jensen medium in the presence of $5 \%$ $\mathrm{NaCl}$. Growth of M. chelonae and isolates of the new taxon was inhibited by $5 \% \mathrm{NaCl}$ when incubated at $30{ }^{\circ} \mathrm{C}$; however, $25-50 \%$ growth compared with positive controls was observed, and growth was not totally absent, as reported previously (Kent \& Kubica, 1985; Springer et al., 1995; Wallace et al., 1993b). No growth was observed on Löwenstein-Jensen medium with $5 \%$ $\mathrm{NaCl}$ when $M$. chelonae and isolates of the new taxon were incubated at $35^{\circ} \mathrm{C}$. Growth of M. abscessus and strain ATCC 35751 in the presence of $5 \% \mathrm{NaCl}$ was unaffected by temperature $\left(30\right.$ or $\left.35^{\circ} \mathrm{C}\right)$, although the M. abscessus type strain, ATCC $19977^{\mathrm{T}}$, showed some degree of inhibition at both temperatures.

Previous disc-diffusion susceptibility studies of $M$. abscessus have shown that kanamycin disc zones of inhibition are larger than those for amikacin. A useful marker for the new taxon was that amikacin disc zones were generally equivalent to or larger than those for kanamycin and the isolates were resistant to cefoxitin and tobramycin. At least two of the three markers were present in 17/18 (95\%) of isolates tested.

On the basis of the observed phenotypic (susceptibility) and genotypic characteristics that differentiate isolates of the new taxon from those of other species of Mycobacterium, we propose the name Mycobacterium immunogenum sp. nov. for these isolates. The specific epithet refers to the association of these mycobacterial isolates with cases of HP (Bolan et al., 1985; Kreiss \& Cox-Ganser, 1997; Muilenberg et al., 1993). 


\section{Differentiation of $M$. immunogenum from related species by PRA}

The PRA patterns of a $439 \mathrm{bp}$ fragment of the hsp65 gene of $M$. immunogenum are distinguishable from those of $M$. abscessus and $M$. chelonae and include: 315 and $130 \mathrm{bp}$ bands with BstEII; 140 and $70 \mathrm{bp}$ bands with HaeIII; 235, 120 and 65 bp bands with HhaI ; 260 and 180 bp bands with MspI; a 385 bp band with HinfI; and 260 and $80 \mathrm{bp}$ bands with BsaHI. Differentiation of $M$. immunogenum from M. abscessus and $M$. chelonae can be accomplished with as few as two enzymes, e.g. BstEII and HaeIII, BstEII and $B s a \mathrm{HI}$ or MspI and HinfI.

\section{Description of Mycobacterium immunogenum sp. nov.}

Mycobacterium immunogenum (im.mu.no.gen'um. N. L. neut. adj. immunogenum eliciting an immune response).

A Gram-positive, acid- and alcohol-fast, curved bacillus that grows aerobically. It does not form spores or aerial hyphae. Visible growth appears in $<7 \mathrm{~d}$. Colonies on Middlebrook 7H10 agar and trypticase soy agar are off-white in colour and usually rough, although smooth forms are observed. No pigment is produced. Growth occurs at 30 and $35^{\circ} \mathrm{C}$, but not at $45^{\circ} \mathrm{C}$. Isolates are susceptible in vitro to amikacin and clarithromycin and resistant to cefoxitin $\left(\mathrm{MIC} \geqslant 256 \mu \mathrm{g} \mathrm{ml}^{-1}\right)$, cefmetazole, ciprofloxacin, doxycycline, imipenem, sulfamethoxazole and tobramycin (MIC $\geqslant 16 \mu \mathrm{g} \mathrm{ml}^{-1}$ ). They are positive for 3-d arylsulfatase activity, negative for iron uptake and nitrate reductase, do not grow on Löwenstein-Jensen medium containing $5 \% \mathrm{NaCl}$ at $35^{\circ} \mathrm{C}$ and do not utilize citrate, D-glucitol (D-sorbitol), $i$-myo-inositol or D-mannitol as sole sources of carbon. Mycolic acids are present and produce HPLC chromatograms typical of the M. abscessus $/ M$. chelonae group. Intact genomic DNA for PFGE can be obtained from all strains.

Two strains, ATCC $700505^{\mathrm{T}}$ (formerly $\mathrm{BH} 29^{\mathrm{T}}$, MC $779^{\mathrm{T}}$ ) and ATCC 700506 (formerly MN 3744, MC 1991), have been deposited with the ATCC (Manassas, VA, USA), with the type strain also deposited in the Mycobacterial Reference Collection of the Institute Pasteur as CIP $106684^{\mathrm{T}}$. The type strain, ATCC $700505^{\mathrm{T}}$, was recovered from a nosocomial pseudooutbreak involving water-borne contamination of an automated bronchoscope washer in St Louis, MO, USA (Fraser et al., 1992), and strain ATCC 700506 was isolated from contaminated industrial MWF (Moore et al., 2000).

\section{ACKNOWLEDGEMENTS}

A portion of this work was presented as an abstract to the 98th General Meeting of the American Society for Microbiology, Atlanta, GA, USA, in May 1998. Contributions of authors: R.W.W., PRA technology and biochemical testing; V.A.S., computerized measurements, data evaluation and preparation of manuscript text and graphics;
E.C.B. and B.S., 16S rRNA sequencing; B.A.B., biochemical and susceptibility testing; V.V., hsp65 gene sequencing and phylogenetic tree; S.H.C. and K.C.J., HPLC analyses; Y.Z., PFGE analyses; G. O., susceptibility testing; H.R., procurement of MWF isolates; M.J.G., DNA-DNA pairing and RFLP experiments; D.R.N., project coordinator; R.J.W., project director, traditional identification of isolates and editing manuscript text and graphics.

This work was supported by the Department of Microbiology and the Center for Pulmonary and Infectious Disease Control at UTHCT. We express our appreciation to Phyllis Pienta, former Collection Manager of Bacteriology, American Type Culture Collection, Manassas, VA, who kindly provided the reference strains used in this study; to Steven J. Moore, Department of Occupational and Environmental Medicine, UTHCT, for facilitating the acquisition of isolates from metalworking fluids; and to Professor Hans G. Trüper, Institute for Microbiology and Biotechnology University of Bonn, Bonn, Germany, for providing the correct Latin nomenclature. We would also like to thank Joanne Woodring for preparation of this manuscript.

This work is in memory of our co-author and friend Vincent Steingrube, a dedicated and meticulous researcher, who passed away prior to completion of this work.

\section{REFERENCES}

Band, J. D., Ward, J. I., Fraser, D. W., Peterson, N. J., Silcox, V. A., Good, R. C., Ostroy, P. R. \& Kennedy, J. (1982). Peritonitis due to a Mycobacterium chelonei-like organism associated with intermittent chronic peritoneal dialysis. J Infect Dis 145, 9-17.

Bernstein, D. I., Lummus, Z. L., Santilli, G., Siskosky, J. \& Bernstein, I. L. (1995). Machine operator's lung. A hypersensitivity pneumonitis disorder associated with exposure to metalworking fluid aerosols. Chest 108, 636-641.

Bolan, G., Reingold, A. L., Carson, L. A. \& 10 other authors (1985). Infections with Mycobacterium chelonei in patients receiving dialysis and using processed hemodialyzers. J Infect Dis 152, 1013-1019.

Brown, B. A., Springer, B., Steingrube, V. A. \& 10 other authors (1999). Mycobacterium wolinskyi sp. nov. and Mycobacterium goodii sp. nov., two new rapidly growing species related to Mycobacterium smegmatis and associated with human wound infections: a cooperative study from the International Working Group on Mycobacterial Taxonomy. Int J Syst Bacteriol 49, 1493-1511.

Butler, W. R. \& Kilburn, J. O. (1990). High-performance liquid chromatography patterns of mycolic acids as criteria for identification of Mycobacterium chelonae, Mycobacterium fortuitum, and Mycobacterium smegmatis. J Clin Microbiol 28, 2094-2098.

Butler, W. R., Cage, G., Desmond, E. \& 9 other authors (1996a). Standardized Method for the HPLC Identification of Mycobacteria. Atlanta, GA: Centers for Disease Control and Prevention.

Butler, W. R., Cage, G., Desmond, E. \& 9 other authors (1996b). Development of a uniform procedure for high-performance liquid chromatography (HPLC) analysis of mycobacteria and validation of a database for an automated recognition software. In Abstracts of the 96th General Meeting of the American Society for Microbiology, abstract U-32, p. 106. Washington, DC: American Society for Microbiology. 
Carson, L. A., Petersen, N. J., Favero, M. S. \& Aguero, S. M. (1978). Growth characteristics of atypical mycobacteria in water and their comparative resistance to disinfectants. Appl Environ Microbiol 36, 839-846.

Carson, L. A., Cusick, L. B., Bland, L. A. \& Favero, M. S. (1988a). Efficacy of chemical dosing methods for isolating nontuberculous mycobacteria from water supplies of dialysis centers. Appl Environ Microbiol 54, 1756-1760.

Carson, L. A., Bland, L. A., Cusick, L. B., Favero, M. S., Bolan, G. A., Reingold, A. L. \& Good, R. C. (1988b). Prevalence of nontuberculous mycobacteria in water supplies of hemodialysis centers. Appl Environ Microbiol 54, 3122-3125.

Collins, C. H., Grange, J. M. \& Yates, M. D. (1984). Mycobacteria in water. J Appl Bacteriol 57, 193-211.

Devallois, A., Goh, K. S. \& Rastogi, N. (1997). Rapid identification of mycobacteria to species level by PCR-restriction fragment length polymorphism analysis of the $h s p 65$ gene and proposition of an algorithm to differentiate 34 mycobacterial species. J Clin Microbiol 35, 2969-2973.

Domenech, P., Jimenez, M. S., Menendez, M. C., Bull, T. J., Samper, S., Manrique, A. \& Garcia, M. J. (1997). Mycobacterium mageritense sp. nov. Int J Syst Bacteriol 47, 535-540.

Fraser, V. J., Jones, M., Murray, P. R., Medoff, G., Zhang, Y. \& Wallace, R. J., Jr (1992). Contamination of flexible fiberoptic bronchoscopes with Mycobacterium chelonae linked to an automated bronchoscope disinfection machine. Am Rev Respir Dis 145, 853-855.

Hoffman, P. C., Fraser, D. W., Robicsek, F., O'Bar, P. R. \& Mauney, C. U. (1981). Two outbreaks of sternal wound infection due to organisms of the Mycobacterium fortuitum complex. J Infect Dis 143, 533-542.

Hultman, T., Stahl, S., Hornes, E. \& Uhlen, M. (1989). Direct solid phase sequencing of genomic and plasmid DNA using magnetic beads as solid support. Nucleic Acids Res 17, 4937-4946.

Jost, K. C., Jr. \& Dunbar, D. (1992). Automated identification of mycobacteria by high-performance liquid chromatography using computer-aided pattern recognition algorithms. In Abstracts of the 92nd General Meeting of the American Society for Microbiology, abstract U69, p. 177. Washington, DC: American Society for Microbiology.

Jost, K. C., Jr, Dunbar, D. F., Barth, S. S., Headley, V. L. \& Elliott, L. B. (1995). Identification of Mycobacterium tuberculosis and $M$. avium complex directly from smear-positive sputum specimens and BACTEC 12B cultures by high-performance liquid chromatography with fluorescence detection and computer-driven pattern recognition models. J Clin Microbiol 33, 1270-1277.

Kapur, V., Li, L. L., Hamrick, M. R. \& 10 other authors (1995). Rapid mycobacterium species assignment and unambiguous identification of mutations associated with antimicrobial resistance in Mycobacterium tuberculosis by automated DNA sequencing. Arch Pathol Lab Med 119, 131-138.

Kazda, J., Müller, H.-J., Stackebrandt, E., Daffe, M., Müller, K. \& Pitulle, C. (1992). Mycobacterium madagascariense sp. nov. Int $J$ Syst Bacteriol 42, 524-528.

Kent, P. T. \& Kubica, G. P. (1985). Public Health Mycobacteriology. A Guide for the Level III Laboratory. Atlanta, GA: US Department of Health and Human Resources, Public Health Services, Centers for Disease Control.

Kirschner, P., Kiekenbeck, M., Meissner, D., Wolters, J. \& Böttger, E. C. (1992a). Genetic heterogeneity within Mycobacterium fortuitum complex species: genotypic criteria for identification. J Clin Microbiol 30, 2772-2775.

Kirschner, P., Teske, A., Schröder, K.-H., Kroppenstedt, R. M., Wolters, J. \& Böttger, E. C. (1992b). Mycobacterium confluentis sp. nov. Int J Syst Bacteriol 42, 257-262.

Kirschner, P., Meier, A. \& Böttger, E. C. (1993a). Genotypic identification and detection of mycobacteria - facing novel and uncultured pathogens. In Diagnostic Molecular Microbiology. Principles and Applications, pp. 173-190. Edited by D. H. Persing, T. F. Smith, F. C. Tenover \& T. J. White. Washington, DC: American Society for Microbiology.

Kirschner, P., Springer, B., Vogel, U., Meier, A., Wrede, A., Kiekenbeck, M., Bange, F. C. \& Böttger, E. C. (1993b). Genotypic identification of mycobacteria by nucleic acid sequence determination: report of a 2-year experience in a clinical laboratory. J Clin Microbiol 31, 2882-2889.

Kreiss, K. \& Cox-Ganser, J. (1997). Metalworking fluid-associated hypersensitivity pneumonitis: a workshop summary. Am J Ind Med 32, 423-432.

Kuritsky, J. N., Bullen, M. G., Broome, C. V., Silcox, V. A., Good, R. C. \& Wallace, R. J., Jr (1983). Sternal wound infections and endocarditis due to organisms of the Mycobacterium fortuitum complex. Ann Intern Med 98, 938-939.

Lowry, P. W., Jarvis, W. R., Oberle, A. D., Bland, L. A., Silberman, R., Bocchini, J. A., Jr, Dean, H. D., Swenson, J. M. \& Wallace, R. J., Jr (1988). Mycobacterium chelonae causing otitis media in an ear-nose-and-throat practice. $N$ Engl J Med 319, 978-982.

Maloney, S., Welbel, S., Daves, B. \& 9 other authors (1994). Mycobacterium abscessus pseudoinfection traced to an automated endoscope washer: utility of epidemiologic and laboratory investigation. J Infect Dis 169, 1166-1169.

Moore, J. S., Christensen, M., Wilson, R. W., Wallace, R. J., Jr, Zhang, Y., Nash, D. R. \& Shelton, B. (2000). Mycobacterial contamination of metalworking fluids: involvement of a possible new taxon of rapidly growing mycobacteria. Am Ind Hyg Assoc J 61, 205-213.

Muilenberg, M. L., Burge, H. A. \& Sweet, T. (1993). Hypersensitivity pneumonitis and exposure to acid-fast bacilli in coolant aerosols. Abstract 682. J Allergy Clin Immunol 91, 311.

Petersen, K., Bus, N., Walter, V. \& Chenoweth, C. (1994). Pseudoepidemic of Mycobacterium abscessus associated with bronchoscopy. Abstract S32. Infect Control Hosp Epidemiol 15(2) (Suppl.), P30.

Picardeau, M., Prod'Hom, G., Raskine, L., LePennec, M. P. \& Vincent, V. (1997). Genotypic characterization of five subspecies of Mycobacterium kansasii. J Clin Microbiol 35, 25-32.

Pitulle, C., Dorsch, M., Kazda, J., Wolters, J. \& Stackebrandt, E. (1992). Phylogeny of rapidly growing members of the genus Mycobacterium. Int J Syst Bacteriol 42, 337-343.

Ringuet, H., Akoua-Koffi, C., Honore, S., Varnerot, A., Vincent, V., Berche, P., Gaillard, J. L. \& Pierre-Audigier, C. (1999). hsp65 sequencing for identification of rapidly growing mycobacteria. $J$ Clin Microbiol 37, 852-857.

Rogall, T., Wolters, J., Flohr, T. \& Böttger, E. C. (1990). Towards a phylogeny and definition of species at the molecular level within the genus Mycobacterium. Int J Syst Bacteriol 40, 323-330.

Schulze-Röbbecke, R., Janning, B. \& Fischeder, R. (1992). Occurrence of mycobacteria in biofilm samples. Tubercule Lung Dis 73, 141-144.

Shinnick, T. M. (1987). The 65-kilodalton antigen of Mycobacterium tuberculosis. J Bacteriol 169, 1080-1088. 
Silcox, V. A., Good, R. C. \& Floyd, M. M. (1981). Identification of clinically significant Mycobacterium fortuitum complex isolates. J Clin Microbiol 14, 686-691.

Springer, B., Böttger, E. C., Kirschner, P. \& Wallace, R. J., Jr (1995). Phylogeny of the Mycobacterium chelonae-like organism based on partial sequencing of the 16S rRNA gene and proposal of Mycobacterium mucogenicum sp. nov. Int J Syst Bacteriol 45, 262-267.

Stahl, D. A. \& Urbance, J. W. (1990). The division between fastand slow-growing species corresponds to natural relationships among the mycobacteria. J Bacteriol 172, 116-124.

Steingrube, V. A., Gibson, J. L., Brown, B. A., Zhang, Y., Wilson, R. W., Rajagopalan, M. \& Wallace, R. J., Jr (1995a). PCR amplification and restriction endonuclease analysis of a 65 kilodalton heat shock protein gene sequence for taxonomic separation of rapidly growing mycobacteria. J Clin Microbiol 33, 149-153.

Steingrube, V. A., Gibson, J. L., Brown, B. A., Zhang, Y., Wilson, R. W., Rajagopalan, M. \& Wallace, R. J., Jr (1995b). Erratum. PCR amplification and restriction endonuclease analysis of a 65-kilodalton heat shock protein gene sequence for taxonomic separation of rapidly growing mycobacteria. J Clin Microbiol 33, 1686.

Steingrube, V. A., Brown, B. A., Gibson, J. L., Wilson, R. W. Brown, J., Blacklock, Z., Jost, K., Ulrich, R. F. \& Wallace, R. J., Jr (1995c). DNA amplification and restriction endonuclease analysis for differentiation of 12 species and taxa of Nocardia, including recognition of four new taxa within the Nocardia asteroides complex. J Clin Microbiol 33, 3096-3101.

Steingrube, V. A., Wilson, R. W., Brown, B. A., Jost, K. C., Jr Blacklock, Z., Gibson, J. L. \& Wallace, R. J., Jr (1997). Rapid identification of clinically significant species and taxa of aerobic actinomycetes, including Actinomadura, Gordona, Nocardia, Rhodococcus, Streptomyces, and Tsukamurella isolates, by DNA amplification and restriction endonuclease analysis. $J$ Clin Microbiol 35, 817-822.

Swanson, D. S., Pan, X. \& Musser, J. M. (1996). Identification and subspecific differentiation of Mycobacterium scrofulaceum by automated sequencing of a region of the gene (hsp65) encoding a 65-kilodalton heat shock protein. J Clin Microbiol 34, 3151-3159.

Swenson, J. M., Wallace, R. J., Jr, Silcox, V. A. \& Thornsberry, C. (1985). Antimicrobial susceptibility of five subgroups of $\mathrm{Myco-}$ bacterium fortuitum and Mycobacterium chelonae. Antimicrob Agents Chemother 28, 807-811.

Szabo, I. \& Sarkozi, K. (1980). M. chelonae endemy after heart surgery with fatal consequences. Am Rev Respir Dis 121, 607.

Taylor, T. B., Patterson, C., Hale, Y. \& Safranek, W. W. (1997). Routine use of PCR-restriction fragment length polymorphism analysis for identification of mycobacteria growing in liquid media. J Clin Microbiol 35, 79-85.

Telenti, A., Marchesi, F., Balz, M., Bally, F., Böttger, E. C. \& Bodmer, T. (1993). Rapid identification of mycobacteria to the species level by polymerase chain reaction and restriction enzyme analysis. J Clin Microbiol 31, 175-178.
Tenover, F. C., Arbeit, R. D., Goering, R. V., Mickelsen, P. A., Murray, B. E., Persing, D. H. \& Swaminathan, B. (1995). Interpreting chromosomal DNA restriction patterns produced by pulsed-field gel electrophoresis: criteria for bacterial strain typing. J Clin Microbiol 33, 2233-2239.

Tsukamura, M. (1981). Numerical analysis of rapidly growing, nonphotochromogenic mycobacteria, including Mycobacterium agri (Tsukamura 1972) Tsukamura sp. nov., nom. rev. Int J Syst Bacteriol 31, 247-258.

Tsukamura, M. (1984). Identification of Mycobacteria. Obu, Aichi, Japan: Mycobacteriosis Research Laboratory of the National Chubu Hospital.

Villaneuva, A., Calderon, R. V., Vargas, B. A., Ruiz, F., Aguero, S., Zhang, Y., Brown, B. A. \& Wallace, R. J., Jr (1997). Report on an outbreak of postinjection abscesses due to Mycobacterium abscessus, including management with surgery and clarithromycin therapy and comparison of strains by random amplified polymorphic DNA polymerase chain reaction. Clin Infect Dis 24, 1147-1153.

Wallace, R. J., Jr, Brown, B. A., Silcox, V. A. \& 8 other authors (1991a). Clinical disease, drug susceptibility, and biochemical patterns of the unnamed third biovariant complex of Mycobacterium fortuitum. J Infect Dis 163, 598-603.

Wallace, R. J., Jr, Brown, B. A. \& Onyi, G. O. (1991b). Susceptibilities of Mycobacterium fortuitum biovar. fortuitum and the two subgroups of Mycobacterium chelonae to imipenem, cefmetazole, cefoxitin, and amoxicillin-clavulanic acid. Antimicrob Agents Chemother 35, 773-775.

Wallace, R. J., Jr, Zhang, Y., Brown, B. A., Fraser, V., Mazurek, G. H. \& Maloney, S. (1993a). DNA large restriction fragment patterns of sporadic and epidemic nosocomial strains of Mycobacterium chelonae and Mycobacterium abscessus. J Clin Microbiol 31, 2697-2701.

Wallace, R. J., Jr, Silcox, V. A., Tsukamura, M., Brown, B. A., Kilburn, J. O., Butler, W. R. \& Onyi, G. (1993b). Clinical significance, biochemical features, and susceptibility patterns of sporadic isolates of the Mycobacterium chelonae-like organism. J Clin Microbiol 31, 3231-3239.

Wallace, R. J., Jr, Brown, B. A. \& Griffith, D. E. (1998). Nosocomial outbreaks/pseudo-outbreaks caused by nontuberculous mycobacteria. Annu Rev Microbiol 52, 453-490.

Wilson, R. W., Steingrube, V. A., Brown, B. A. \& 7 other authors (1997). Recognition of a Nocardia transvalensis complex by resistance to aminoglycosides, including amikacin, and PCRrestriction fragment length polymorphism analysis. $J$ Clin Microbiol 35, 2235-2242.

Wilson, R. W., Steingrube, V. A., Brown, B. A. \& Wallace, R. J., Jr (1998). Clinical application of PCR-restriction enzyme pattern analysis for rapid identification of aerobic actinomycete isolates. J Clin Microbiol 36, 148-152.

Zhang, Y., Rajagopalan, M., Brown, B. A. \& Wallace, R. J., Jr (1997). Randomly amplified polymorphic DNA PCR for comparison of Mycobacterium abscessus strains from nosocomial outbreaks. J Clin Microbiol 35, 3132-3139. 